This item was submitted to Loughborough's Research Repository by the author.

Items in Figshare are protected by copyright, with all rights reserved, unless otherwise indicated.

Effect of tongue jewellery and orthodontist metallic braces on the SAR due to mobile phones in different anatomical human head models including children

PLEASE CITE THE PUBLISHED VERSION

PUBLISHER

(C) Institute of Electrical and Electronics Engineers (IEEE)

LICENCE

CC BY-NC-ND 4.0

REPOSITORY RECORD

Whittow, W.G., R.M. Edwards, C.J. Panagamuwa, and J.C. Vardaxoglou. 2019. "Effect of Tongue Jewellery and Orthodontist Metallic Braces on the SAR Due to Mobile Phones in Different Anatomical Human Head Models Including Children". figshare. https://hdl.handle.net/2134/3342. 
This item was submitted to Loughborough's Institutional Repository by the author and is made available under the following Creative Commons Licence conditions.

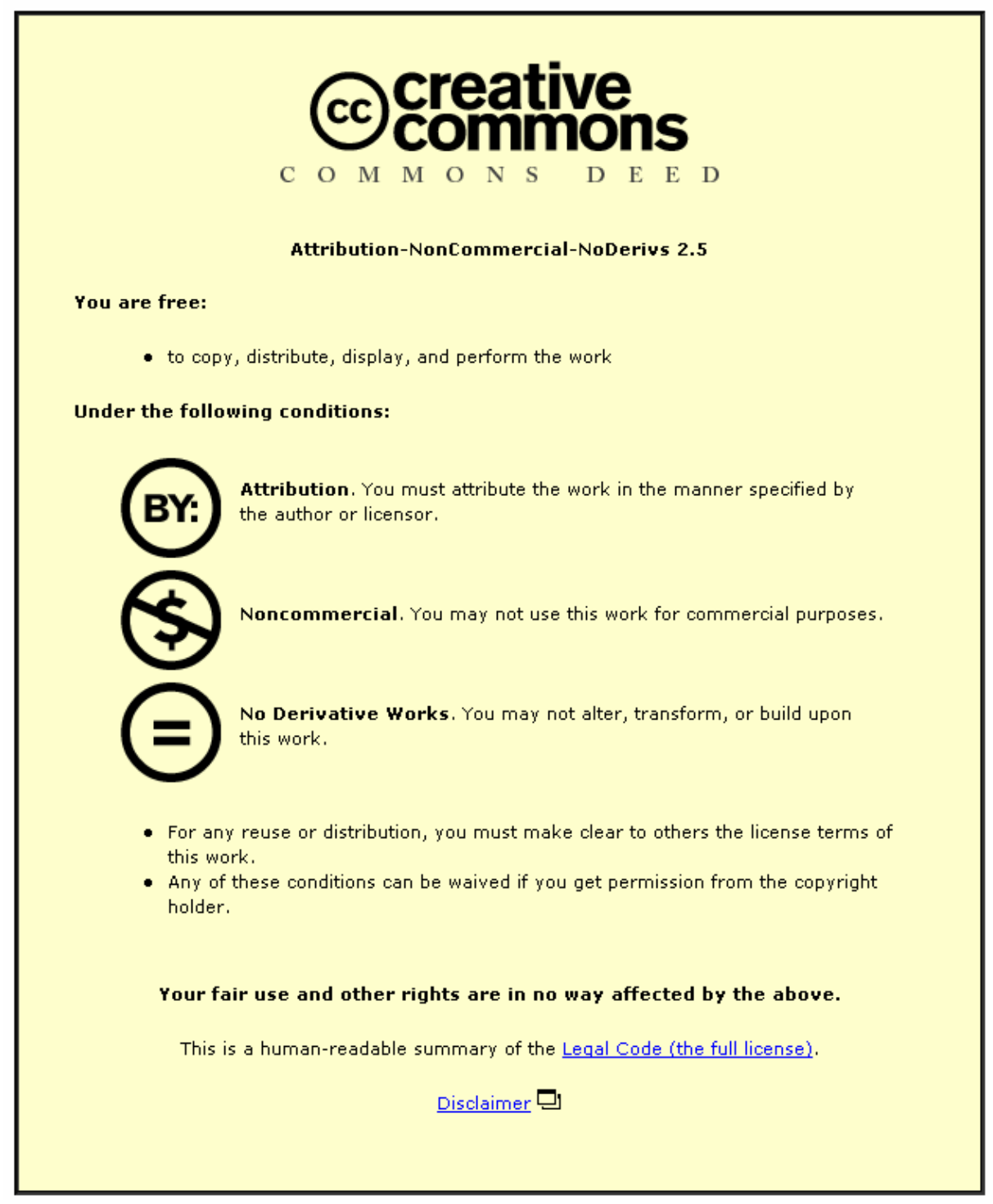

For the full text of this licence, please go to: http://creativecommons.org/licenses/by-nc-nd/2.5/ 


\title{
EFFECT OF TONGUE JEWELLERY AND ORTHODONTIST METALLIC BRACES ON THE SAR DUE TO MOBILE PHONES IN DIFFERENT ANATOMICAL HUMAN HEAD MODELS INCLUDING CHILDREN
}

\author{
W. G. Whittow (1), R. M. Edwards (1), C. J. Panagamuwa (1) and J. C. Vardaxoglou (1) \\ (1) Department of Electronic \& Electrical Engineering, Loughborough University, \\ Leicestershire, LE11 3TU. UK. \\ Email:W.G.Whittow@lboro.ac.uk; Email:R.M.Edwards@lboro.ac.uk \\ Email: C.J.Panagamuwa@lboro.ac.uk; Email: J.C.Vardaxoglou@lboro.ac.uk
}

\begin{abstract}
This paper has used the Finite-difference Time-domain (FDTD) computer simulation technique to investigate Specific Absorption Rates (SAR) in different human head models with metallic jewellery. A dipole excitation has been placed in front of the nose of 4 anatomical heads including a 5 year old and a 12 year old child's head. Metallic tongue jewellery and orthodontist metallic braces were added to the models and the SAR was investigated over a range of communication frequencies.
\end{abstract}

\section{Introduction}

There has been public and scientific comment that the radiation from mobile devices may affect human health. Recent estimates suggest there are over a billion mobile phones users in the world Advances in technology means that current and future communications are likely to be used in front of the face, like PDAs. Many of the people who use communications enabled devices may also wear metallic jewellery or have metallic objects in close proximity to their head. In previous works, the authors $[1,2]$ have found that metallic spectacles can significantly increase the SAR in the eyes and head. Please see [1-3] for a more complete literature review of bioelectromagnetics and the effects of metallic objects on SAR. Generally, previous research has typically used either a homogenous head or one heterogeneous head to investigate the SAR levels from mobile devices. However, every human has a different shape and size as well as different internal properties. Therefore, using a selection of anatomically realistic heads allows us to make more general conclusions. Comparison of the different digital human head models shows that the identification of different tissues from the MRI data varies considerably between different laboratories. This highlights the importance of using more than one head model to assess radio frequency radiation levels inside a head by extrapolation from illuminating fields. Since possible effects from SAR are likely to be strongly linked to the mass of the absorbing body, it is also interesting to consider the SAR in a child's head. This paper considers the effect of tongue piercings and orthodontist braces on the SAR in the head.

\section{Description of model}

An independent 3D FDTD code [1, 2] has been written. Perfectly Matched Layers (PML) absorbing boundary conditions are used to terminate the grid. The PML is eight cells thick and is positioned at least twelve cells from the head. The frequency range considered in this paper is 0.5 to $4.6 \mathrm{GHz}$. The Yee cell size used throughout this paper is $2 \mathrm{~mm}$. The lowest number of cells per wavelength was always greater than four which provides reasonable results [3]. Note, that this is less important in this paper, as the jewellery considered only has an effect at lower frequencies where the sampling is much greater than four cells per wavelength. Both horizontally ( $\mathrm{Y}$ axis) and vertically ( $\mathrm{Z}$ axis) alligned dipole models have been used in this paper. The centre of the dipole is positioned $80 \mathrm{~mm}$ (along the $\mathrm{X}$ axis) in front of the tip of the nose of each head and is fed with a sinusoidal CW source. The tangential E-field components are set to zero along the length of the dipole [1]. All results in this paper are normalised to $1 \mathrm{~W}$ input power and the frequency of excitation is varied. The length of the dipole changed with frequency. The metallic objects were modelled using metallic Yee cells, by setting the conductivity of the cells equal to the conductivity of copper [1]. The authors have previously shown that the choice of metal has negligible effect on SAR values. The SAR is calculated with the twelve-field approach [1]. The objects investigated in this paper were $2 \mathrm{~mm}$ thick (1 Yee cell).

Four different anatomically accurate head models have been used in this paper. The Brooks head is an adult male head matrix provided by Brooks Air Force (http://www.brooks.af.mil/) [1]. The head is based on The Visible Human Project and has 25 tissue types. The Bradford head is an adult male with 15 different tissues [4]. The two child head models were provided by Réseau National de Recherches en Télécommunications 
((http://www.tsi.enst.fr/adonis/). The $\mathbf{5}$ year old child's head contains 11 tissues while the 12 year old child's head contains 14 tissues. The heads have a $2 \mathrm{~mm}$ resolution. The 4 head models are shown in Figure 1 along with the geometry of the dipoles and metallic jewellery. The densities and dielectric properties of the tissues in the Brooks head at $1800 \mathrm{MHz}$ are shown in [2].

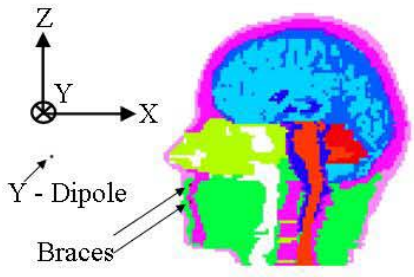

(a): Bradford head

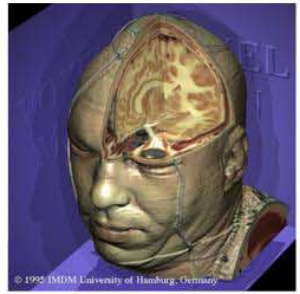

(b): Brooks head

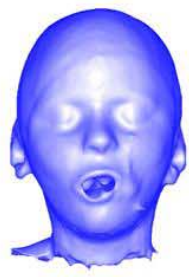

(c): 5 year old head

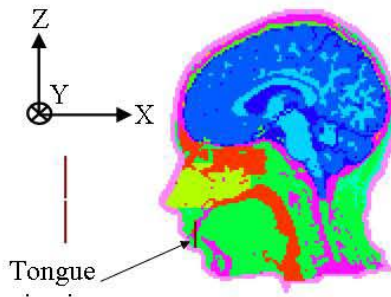

(d): 12 year old head

Figure 1. The 4 anatomical head models: (a) shows the Bradford head with braces and Y orientated dipole; (b) a visualisation of the Brooks head [5]; (c) the 5 year old head and (d) the 12 year old head with a $22 \mathrm{~mm}$ tongue piercing and a $\mathrm{Z}$ directed dipole.

\section{Results}

With a dipole in front of the nose, the maximum $1 \mathrm{~g}$ SAR generally occurs at the tip of the nose. It was found that the metallic objects that were orientated perpendicular to the dipole had negligible effect over the entire frequency range considered. Therefore, the tongue piercings was excited with a $\mathrm{Z}$ directed dipole, see Figure 1 (d) and the orthodontist braces were excited with a Y directed dipole, see Figure 1 (a).

The first part of this paper considers metallic tongue piercings on three different heads. The 5 year old head model was not considered for this section as the model has an open mouth, see Figure 1 (c). Tongue piercings are typically between 6 and $22 \mathrm{~mm}$ long. In this work, $22 \mathrm{~mm}$ long metallic pins were pierced through the muscle tissue in the mouth. The pins were vertically orientated along the $Z$ axis; see Figure 1 (d). The 10g SAR results are shown in Figure 2. The different sizes and internal structures in the three head models produced different $10 \mathrm{~g}$ SAR values over the frequency range. Both the Brooks and Bradford heads produced the largest SAR values between 1.5 and $1.9 \mathrm{GHz}$. The $22 \mathrm{~mm}$ tongue piercing had negligible effect on the $10 \mathrm{~g}$ SAR (or 1g SAR) in the Brooks and Bradford heads at all frequencies considered. The effect on the 12 year old head was slightly greater but still very small. $6 \mathrm{~mm}$ and $14 \mathrm{~mm}$ long tongue piercings were also considered and also had negligible effect.

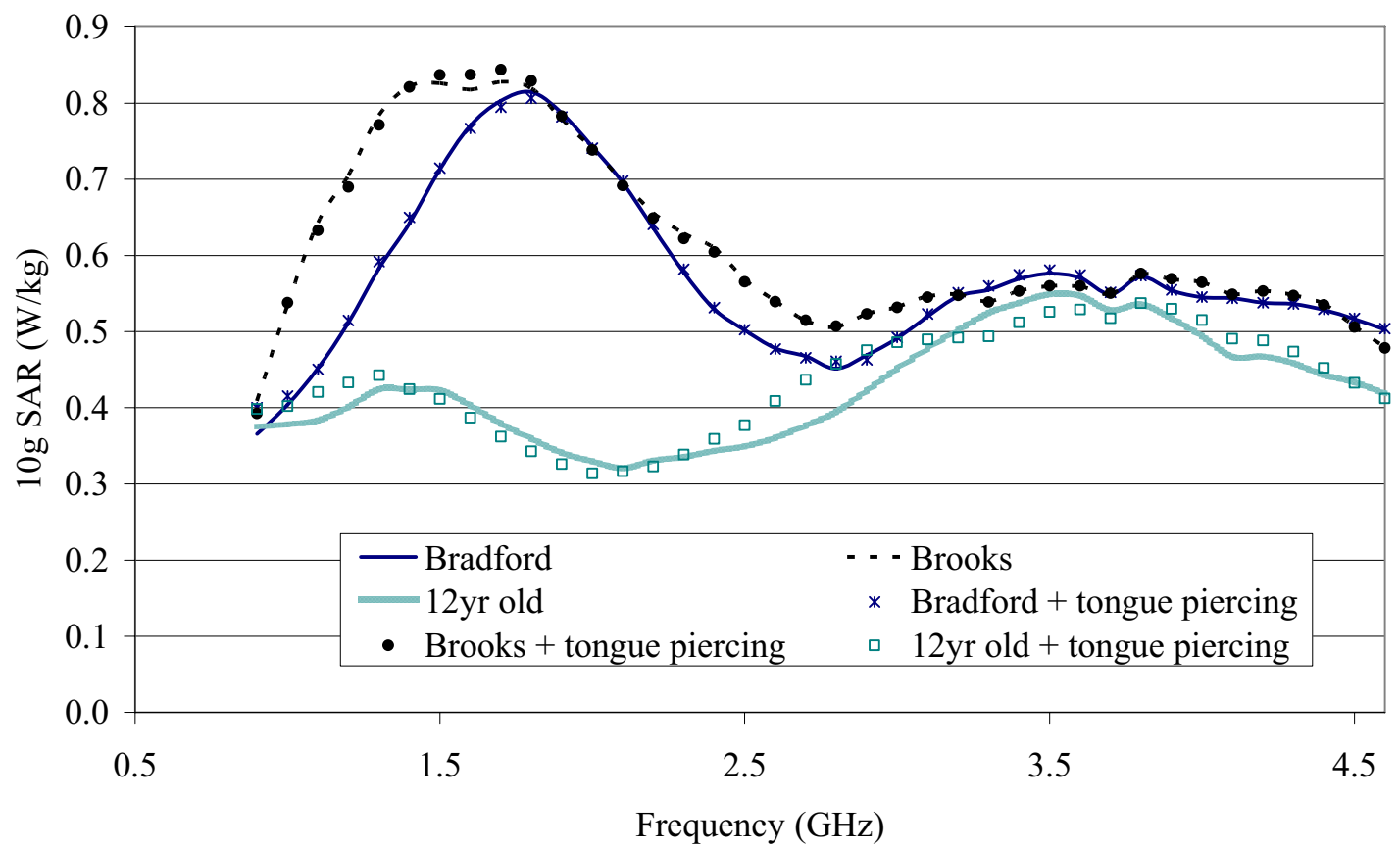

Figure 2. The 10g SAR in different heads as a function of frequency with a $Z$ directed dipole source with a $22 \mathrm{~mm}$ long tongue piercing aligned along the central $Z$ axis. 
Metallic orthodontist braces were added to four anatomical heads; see Figure 1 (a). The braces consisted of two lines of metallic Yee cells that followed the front of both the top and bottom rows of teeth in a horse-shoe shape. Note, only the Brooks head had the teeth identified as a specific tissue. For the other heads, the braces followed the line of bone tissue in the mouth that represented the teeth. It was hypothesized that the metallic plates that are commonly added to braces could form an antenna array inside the mouth. This was investigated by adding an array of metallic plates $6 \mathrm{~mm}$ high and $4 \mathrm{~mm}$ wide every $10 \mathrm{~mm}$ along the line of the braces. However, it was found that with both orientations of dipole, the braces consisting of 2 lines of Yee cells and the arrays of metallic plates had negligible difference to the braces modelled just by a line of metallic Yee cells. Therefore, the results in Figure 3 and Figure 4 are with the braces made out of two horse-shoe shaped lines of metallic Yee cells in two XZ horizontal planes and do not include metallic plates.

The results in Figure 3 show the effect of braces on the $10 \mathrm{~g}$ SAR in four different anatomical heads as a function of frequency. Note, that adding the braces to the heads had negligible effect from $3 \mathrm{GHz}$ to $4.6 \mathrm{GHz}$ and therefore the results have not been included to allow the effect of the braces to be more clearly seen in the figure. The metallic braces generally increase the $10 \mathrm{~g}$ SAR in the different heads between 0.8 and $1.7 \mathrm{GHz}$. The largest effect was found with the Brooks head at $0.9 \mathrm{GHz}$, where braces increased the $10 \mathrm{~g}$ SAR by 1.7 times (and the $1 \mathrm{~g}$ SAR by 2.2 times). Braces increased the $10 \mathrm{~g}$ SAR (and $1 \mathrm{~g} \mathrm{SAR}$ ) at approximately $1.1 \mathrm{GHz}$ by 1.5 times in the Bradford and 12 year old heads. The power absorbed in the whole head was increased by up to $10 \%$. The metallic braces had effects at slightly different frequencies in the different models. This was due the length of the braces and the surrounding tissues in the four heads.

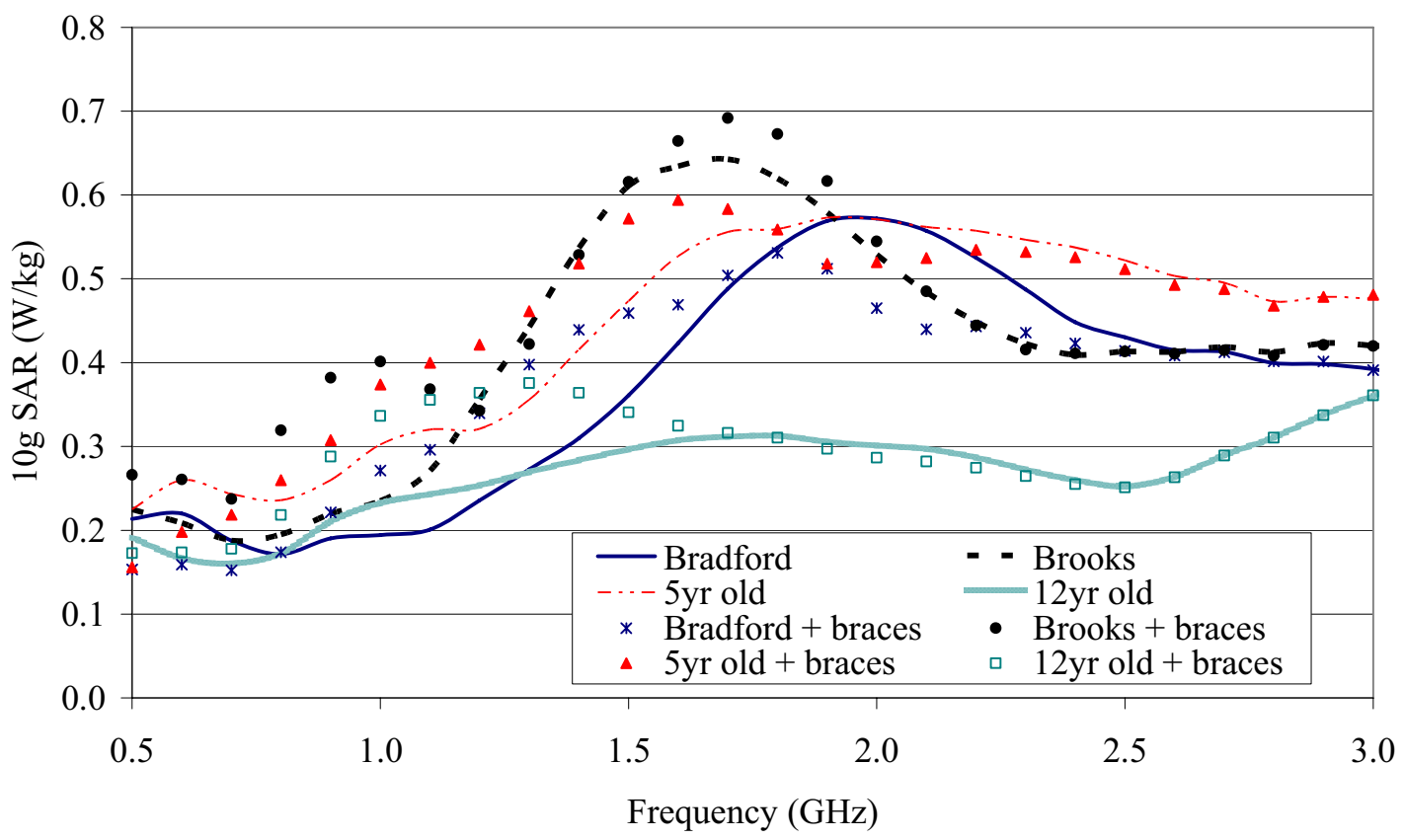

Figure 3. The 10g SAR in different heads as a function of frequency with a $\mathrm{Y}$ directed dipole source with metallic braces in the $\mathrm{XZ}$ plane.

Comparison of Figure 2 and Figure 3 shows that a $\mathrm{Z}$ directed dipole produced larger $10 \mathrm{~g}$ SAR, values at all frequencies considered, than the same head excited with a Y directed dipole. This was still the case when the braces were added to the heads with a Y directed dipole. Although, braces increased the SAR, the effects were less than changing the orientation of the source.

The average SAR in the eyes of the different heads was also considered, with and without metallic orthodontist braces, and the results are shown in Figure 4. The eyes are mainly homogeneous spherical structures that can resonate $[1,2]$ at different frequencies. All the head models have closed eyelids. Closed eyelids can increase the SAR in the eyes as the layers of skin and fat act as a matching layer between the air and the eye [2]. The Bradford eye included humor, lens and sclera tissues. The Brooks eye included humor, lens, sclera and cornea. The eyes in the child head models only consisted of one tissue. The figure shows that the eyes in both the Brooks head and the 5 year old head resonate around $1.9 \mathrm{GHz}$, while the eyes in the Bradford and 12 year old head have the highest SAR at lower frequencies.

The metallic braces had negligible effect in the eyes between 1.8 and $3 \mathrm{GHz}$ as shown in Figure 4 . This was also the case between 3 and $4.6 \mathrm{GHz}$. However, between 0.5 and $1.8 \mathrm{GHz}$, the metallic braces could increase and 
decrease the average SAR in the eyes. The size of the eyes affected the sensitivity of the average SAR. The 5 year old child had the smallest eyes and the braces increased the average SAR in the eyes by over 1.7 times at $0.8 \mathrm{GHz}$. The average SAR in the Bradford head was increased by 1.4 times at $0.7 \mathrm{GHz}$. The Brooks model and the 12 year old child's head have the largest eyes and the braces increased the SAR in these models by 1.2 times at $0.7 \mathrm{GHz}$.

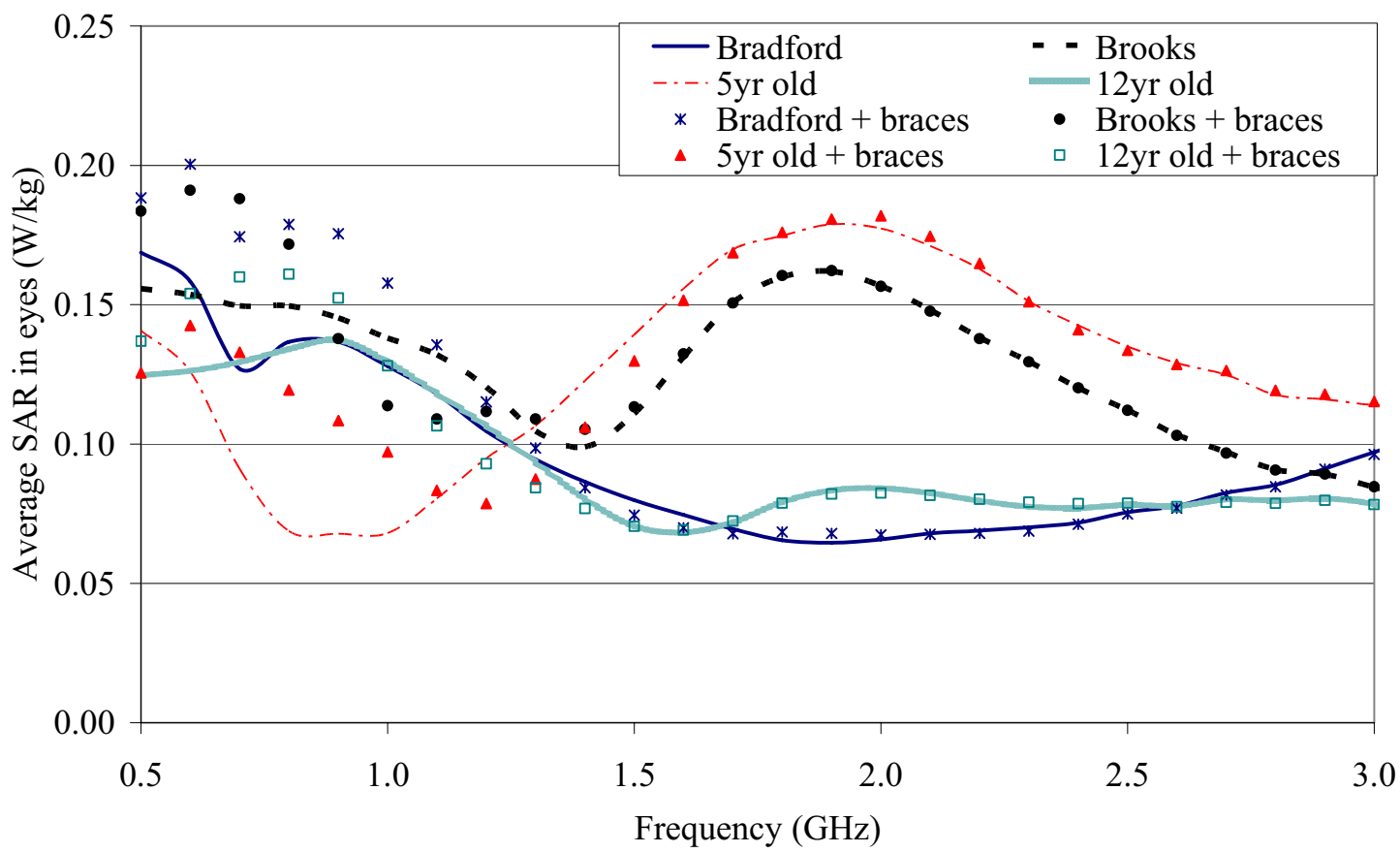

Figure 4. The average SAR in the eyes of different heads as a function of frequency with a Y-directed dipole source with metallic braces in the $\mathrm{XZ}$ plane.

\section{Conclusions}

The FDTD method has been used to investigate the effects of the SAR in four anatomical head models with metallic jewellery. Metallic tongue piercings were found to have negligible effects at all frequencies considered. However, metallic braces added to the teeth, could double the $1 \mathrm{~g}$ and $10 \mathrm{~g}$ SAR. The different head models behaved in a reasonably similar way despite being different sizes and containing different tissues. Differences were observed between the models but there were no obvious differences between the heads of adults and children without the metallic jewellery. The main difference with metallic braces, was the size of the teeth, which directly affected the size of the braces. It is also possible that the electrical properties of the surrounding tissues may alter the resonance size of the braces. The braces on the teeth were also found to increase the SAR in the eyes at low frequencies.

\section{References}

[1] W. G. Whittow and R. M. Edwards, "A study of changes to specific absorption rates in the human eye close to perfectly conducting spectacles within the radio frequency range 1.5 to $3.0 \mathrm{GHz}$," IEEE Trans. Antennas and Propagation, vol. 52, pp. 3207-3212, 2004.

[2] W. G. Whittow and R. M. Edwards, "Applications of a genetic algorithm for identification of maxima in specific absorption rates in the human eye close to perfectly conducting spectacles," IEE Proceedings Science, Measurement \& Technology, vol. 152, pp. 89-96, 2005.

[3] P. J. Dimbylow and O. P. Gandhi, "Finite-difference time-domain calculations of SAR in a realistic heterogeneous model of the head for plane-wave exposure from $600 \mathrm{MHz}$ to $3 \mathrm{GHz}$," Physics in Medicine and Biology, vol. 36, pp. 1075-1089, 1991.

[4] P. Olley and P. S. Excell, "Classification of a High-Resolution Voxel Image of a Human Head," in 'Voxel Phantom Development', Proceedings of an International Workshop at the National Radiological Protection Board, Chilton, UK., 1995, pp. 16-23.

[5] U. Tiede, T. Schiemann, and K. H. Höhne, "Visualizing the Visible Human," IEEE Comput. Graphics Appl., vol. 16, pp. 7-9, 1996. 